\title{
Effects of Tramadol Addiction on Brain of Adult Male Albino Rats and Role of lofexidine during Withdrawal Period: A Biochemical, Histopathological and Immunohistochemical Study
}

\author{
Ahmed K Elden Elfeky ${ }^{1}$ and Abdelnaby S Mohamed ${ }^{2}$ \\ ${ }^{1}$ Department of Forensic Medicine and Clinical Toxicology. \\ ${ }^{2}$ Department of pathology. \\ Faculty of Medicine, Menoufia University, Menoufia, Egypt.
}

\begin{abstract}
Background: Tramadol is a synthetic opioid analgesic commonly prescribed for moderate to severe pain, becoming abused more popular among teens in most countries. In addition to the euphoric and mood-enhancing effects sought by tramadol abusers, taking this drug for nonmedical purposes, abusing tramadol can lead to tolerance and dependence. Abusers who continue to take tramadol long enough and at high enough doses will eventually develop a physical dependence on the drug and experience unpleasant, or even dangerous, symptoms of withdrawal if they stop taking the medication. Objective: To study the biochemical, histopathological and immunohistochemical changes of repeated administration of tramadol on the brain cells of male albino rats and role of duration of addiction in the damaging effects produced, and to prove if there is a role for lofexidine in the treatment of tramadol addiction in withdrawal period and detect the changes after recovery period and withdrawal of tramadol .Materials and methods: 100 adult male albino rats were randomly divided into equal 5groups: Group I: (20 rats) Control group: including those given normal feeding. Group II: (20 rats) Tramadol treated group for one month. Group III: (20 rats) Tramadol treated group for 2 months. Group IV: (20 rats) Tramadol treated for one month then given lofexidine for another month during withdrawal. Group V: (20 rats) Tramadol treated for one month and left for another month for recovery. Animals were observed for any behavioral changes throughout the research and recorded. At the end of the experiment animals were scarified by cervical dislocation under inhalation anesthesia, autopsy was done and the brain specimens were obtained, prepared for biochemical study for dopamine level and others preserved for histopathological and immunohistochemical study with their specific procedures. Results: Repeated Tramadol administration resulted in rats behavioral changes( restlessness, irritability defensive aggressive reactions) and produced decreased dopamine levels and significant brain damage in the histopathological and immunohistochemical study that increased with increased period of intake (The maximum damage was recorded in group III with two months tramadol administration, varying degrees of recovery after stoppage of intake were noted in Group V and more improvement by Lofexidine treatment in Group IV). Conclusions: Repeated Tramadol administration causes degenerative changes on the rat brain which increased with increasing the period of this administration. Some improvement was detected after stoppage and more improvement with Lofexidine treatment in withdrawal period.
\end{abstract}

\footnotetext{
Introduction

$\mathrm{N}$ owadays addiction is an increasing social and health problem worldwide despite all efforts to prevent and control it. Opoid analgesics are among the most popular drugs which are being abused (Rafati et al., 2006). Tramadol is a synthetic opioid analgesic commonly prescribed for moderate to severe
}

pain, usual doses being up to $200 \mathrm{mg} / \mathrm{day}$. The maximum allowed daily dose is $400 \mathrm{mg}$ (McKeon et al., 2011).

Tramadol provides analgesia through 3 mechanisms: mu-opioid binding (through its metabolite O-desmethyltramadol), serotonin reuptake 
inhibition and nor-epinephrine reuptake inhibition. (Sansone 2008 and Sansone, 2009).Tramadol is also thought to have some $\mathrm{N}$-methyl-D-aspartate receptor (NMDAR) antagonist effects, which has given it a potential application in neuropathic pain states (Lintzet al.,1998).5-HT2C blockade may also account for its lowering of the seizure threshold could be attributed to tramadol's putative inhibition of gamma-Aminobutyric acid (GABAA) receptor at high doses, sometimes resulting in spontaneous death. (Hara et.al., 2005).

Tramadol can cause a higher incidence of nausea, dizziness, dry mouth, indigestion, abdominal pain, vertigo, vomiting, constipation, drowsiness, headache and loss of appetite, which could deter recreational use. (Langley et al.; 2010) and can cause psychological and physical addiction similar to that of other opiates (Lanier et al., 2010). Tramadol undergoes hepatic metabolism via the cytochrome P450 isozyme to five different metabolites, of these, Tramadol is metabolised to Odesmethyltramadol, which is a more potent opioid has 200 times the $\mu$-affinity of tramadol, and elimination half-life of nine hours, compared with

six hours for tramadol itself (Raffaet al. 2006)

Withdrawal symptoms of tramadol are typical of opiate withdrawal including numbness, tingling, parasthesia, and tinnitus (Epstein et. al.; 2006).

Lofexidine is a structural analogue of clonidine. It is an imidazoline $\alpha 2$-adrenergic receptor agonist. This makes it less likely to cause hypotension than non-selective $\alpha 2$-adrenergic agonists, hypotension and bradycardia, though not as severely as clonidine may cause drowsiness and sedation. It is commonly used to alleviate the physical symptoms of opioid withdrawal. It is approved in the United Kingdom since 1992 in tablet form (Coxand Alcorn 1995).When taken orally lofexidine has a very high bioavailability, a steady state for plasma concentration is reached after approximately 2 days.Lofexidine stimulates receptors in the brain that monitor the levels of adrenaline and noradrenaline in the blood which are significantly elevated during opiate withdrawal causes the brain to reduce its signals to the adrenal medulla, which in turn lowers catecholamine production This central action is responsible for the suppression of opiate withdrawal symptoms. Initial dosage should be $0.8 \mathrm{mg}$ per day in divided doses. The dosage may be increased by increments of 0.4 to $0.8 \mathrm{mg}$ per day up to a maximum of 2.4mg daily. (Zoe Clarke 2007)

Caspases: Apoptosis is a programmed cell death with significant role in development and homeostasis of multicellular organisms. Most of the biological processes during apoptosis are caused by cysteine proteases that are part of a large family of proteins known as caspases. (Waltereit R, Weller M. 2002). They are the central components of apoptotic response and are generally divided into two classes: initiator and the effector caspases which includes caspase-3 (Riedl SJ, ShiY. 2004).

\section{Aim of the work}

To study histo-pathological, immunological and biochemical changes of repeated administration of tramadol on brain cells of male albino rats and to detect changes after withdrawal of tramadol and prove if there is a role for lofexidine in withdrawal of tramadol and role of duration of addiction in damage effects produced.

\section{Materials and Methods: \\ I. Drugs:}

Tramadol (tramadol HCl), 225mg tablets, was obtained from El-Kahera-pharmaceutical Co., Egypt. Detoxydine (Lofexidine Hydrochloride) $0.2 \mathrm{mg}$ Film-Coated Tablets. Produced by Al-Debeiky Pharma Co. For: Delta Pharma Co. Sole Agent: Hope Medical Co.

\section{Animal grouping:}

100 adult male albino rats were randomly divided into 5equal groups:

Group I : (20 rats) control group: including those given normal feeding.

Group II: (20 rats) Tramadol treated group for one month.

Group III: (20 rats) Tramadol treated group for 2 months.

Group IV: (20 rats) Tramadol treated for one month then given Lefoxidine for another month during withdrawal.

Group V: (20 rats) Tramadol treated for one month and left for another month for recovery.

The experiment was carried out on 100 male albino rat weighing $180-200 \mathrm{~g}$ obtained from the breeding animal house of Menoufia University; they were given normal rat chows and water through the experiment. All ethical approved conditions used for animal housing, feeding and handling were considered , animals were left for 2 weeks in a quite environment for acclimatization. The animal utilization protocols were in accordance with the guidelines provided by the Experimental Animal Laboratory, and the study was approved by the Ethical Committee and Council of the General Division for Basic Medical Science. The animals were randomly divided into equal 5groups ( $n=20$ /group). The first control group was administered a normal diet and $1 \mathrm{ml} /$ day normal saline $(0.9 \%)$ orally by gavage and kept for the same period as the rats of other groups The treated groups were administered oral doses of (tramadol $\mathrm{HCl}$ ) suspended in saline solution..

Dependence was induced by giving the therapeutic dose of tramadol hydrochloride which was calculated according to Paget's equation (Paget and Barnes 1964). The therapeutic dose for rat weighting $200 \mathrm{gm}=18 / 1000 \mathrm{x}$ adult human therapeutic daily dose (400 mg) = $7.2 \mathrm{mg}$ (Paget GE, Barnes JM 1964), then the dose was gradually increased by adding the initial calculated therapeutic dose every three days till reaching the dependent dose after one month. The calculated tramadol hydrochloride doses were given orally to each animal by a curved needle -like oral tube that was introduced directly into stomach (a gavage process). Lefoxidine was calculated according to Paget's equation $0.8 \mathrm{mg}$ per day in divided doses with the same procedures as tramadol. Control and treated 
rats were sacrificed at the end of the experiment. Animal painless procedure was conducted with appropriated sedation under light ether inhalation anesthesia to avoid pain and stress

Sample preparation: after autopsy the rat brains were divided into 2 categories for Biochemical study and others for histopathological and immunohistochemical study:

\section{Biochemical indices:}

The brain was transferred to a dry, ice-cold glass plate and dissected into the following regions: cerebral cortex, thalamus and cerebellum. All tissues were patted dry and weighed. Brain tissue samples were stored at $-80 \mathrm{C}$ until analysis. The levels of monoamines (Dopamine) were investigated in the cerebral cortex, thalamus and cerebellum in rats to evaluate the effects of tramadol, recovery period and role of lofexidine on neurotoxicity.

Extraction and Separation: The estimation of Dopamine levels in the rat tissues was carried out according to the fluorometric method described by Ciarlone 1978 ,analyzed for Dopamine fluorescence at excitation and emission wavelengths of 320 and $375 \mathrm{~nm}$, respectively.

II. Histopathological examination: The brain was dissected out for each rat to be received at the pathology department, Faculty of Medicine; Menoufia University preserved in $10 \%$ formalin solution and dehydrated in ascending grades of alcohol. After xylene treatment, the specimens were embedded in paraffin blocks. Five-micron thick; serial sections were cut by microtome and stained with hematoxylin and eosin (H\&E). The stained sections were examined using light microscope according to Bancroft and Gamble.

III. Immunohistochemistry staining (IHS) for Caspase-3

Apoptosis was immune-histochemically localized using Caspase-3 antibodies. Paraffin sections ( $4 \mu \mathrm{m}$ thick) were incubated with a monoclonal caspase-3 antibody using the avidin biotin peroxidase method (Krajewska et al 1997). For the analysis of protein expression related to apoptosis (caspase-3), areas with higher concentration of positive cells ("hot spots" areas) were selected in each slide. This methodology was used because the protein marking was not always observed diffusely in the samples studied. In order to evaluate the staining intensity, we used a semi-quantitative method ( + to +++ ), and also calculated the percentage of stained (positive) cells in relation to the number of total cells.

\section{Statistical Analysis:}

Data were tabulated and statistically analyzed using Statistical Package for the Social Sciences (SPSS) for windows version 16.0. Categorical data were expressed as Mean and Standard Deviation (M and SD) were compared using Anova test. P-value of 0.05 or less is considered significant and P-value of 0.01 or less is considered highly significant

\section{Results}

Behavioral changes and manifestations: behavior. Group I (control): sustained normal

Group II and III (Tramadol Dependent groups): The animals of this group were observed daily. During the first week they behaved normally except for sedation and calmness. During the second week, the rats became restless, irritable and some had tremors one to two hours before the designed dose, after which calmness, laziness and anorexia had developed. As the dose increased the rats became more irritable, some of them developed aggressiveness, yet the manifestations alleviated shortly after the dose. Then after another episode of altered behavioral parameters developed (pronounced defensive behavior, increased fearfulness), salivation, and spasms were also noted on most of the rats. During the last week symptoms like tremors, irritability and salivation were also noted. Convulsions, anorexia and loss of body weight were more exaggerated at the end of the of the first month and more exaggerated till the end of two months.

Group IV (lofexidine treated group): The animals of this group showed manifestations similar to group IV but more milder and improved rapidly.

Group V (Recovery group): The animals of this group were observed daily. During the first week of withdrawal, tremors, irritability, salivation convulsions and anorexia were also noted. But these manifestations gradually improved by time till the end of second month.

\section{Biochemical indices results:}

The levels of monoamines (DA) were investigated in the cerebral cortex, thalamus and cerebellum in rats to evaluate the effects of tramadol, recovery period and role of lofexidine on neurotoxicity. Dopamine content was statistically significantly decreased in all regions of the brain examined in rats treated with tramadol. This decrease was time dependent (more decrease in rats exposed to tramadol for two months). There were statistically significantly increased levels of dopamine after recovery period, more increased levels with lofexidine treated groups. (Table 1,2,3)

\section{Histopathological study of the brain}

Group I (Control group): light microscopic examination of cerebellum region prepared from control group rat's brain showed normal cellular composition in all the three layers (molecular, purkinje and granular). Morphological examination of the cerebral cortex (cc) prepared from control group rat's brain showed the gray matter with its well organized regularly arranged six layers (molecular, external granular, pyramidal, internal granular, ganglionic and the deepest multiform layer).The neurons and the neuroglia cells are normally distributed in the neuropil (fig.1). 
Group II: Treated group which given tramadol for one month: the cerebral cortex showed disorganization of cortical layer, intensively stained focal eosinophilic areas with increased cellularity as well as degenerated neurocytes with dilated blood vessels, apoptotic cells and vacuolation of neuropil.Neuronal cells showed shrunken neurons with pyknotic nuclei and scanty eosinophilic cytoplasm (signs of apoptotic cells) (fig3,5).

cerebellum examination: showed shrunken apoptotic cells as well as degenerated and necrotic cells and red neurons with shifting of the nucleus towards the axon, reduced size of purkenji cells with presence of pyknotic nuclei and vacuolation of the molecular layer (fig2,4).

Group III: Treated group with tramadol for two months, the cerebral cortex showed marked neuronal cell degeneration, extensive neuropil vacuolization, gliosis of the neuropil. Presence of red neurons with prominent perineuronal retraction spaces (Red neurons, markers of apoptosis were evident. A red neuron was defined as a brightly stained neuron with scanty eosinophilic cytoplasm, nuclear pyknosis, and perineural retraction spaces). Congested vascular channels and cell infiltrations .(fig7,10)

Cerebellum examination: showed severe decrease in the number and size of purkinje cells, some purkenji showing also cytoplasmic vacuolation and congested blood vessels. The molecular layer showing fibrosis with presence of some necrotic areas and vacuoles.The section also shows degenerated granular areas which became loosen and separated from each other, purkinje cells lost their normal appearance (fig 6, $8,9,11,12$ )

Group IV: Lofexidine treated group : the cerebral cortex showed nearly normal appearance of the neurons and neuropil, return of brain tissues towards normal morphology as evident by remarkable regression of the total degenerative changes with few degenerated neurons are still present but still different when compared with control. (fig13,14,15,16).

Group V: Recovery group showing slight improvement in the histo-morphological changes (fig17,18,19,20).

Immunohistochemical changes (caspase 3):

Analysis of caspase-3 showed that in the prepared slides of control group showed no immunereactive cells (negative findings, fig 21). Sections of brain of tramadol treated rats for one month (groupII) showing moderately stained immune-reactive cells (intermediate $(++)$,fig22) while sections of brain of tramadol treated rats for two month (group III) showed diffuse intensely stained immune-reactive cell (high +++ ) (fig23 ) while sections of recovery group (group V) showed decreased numbers of immune-reactive cells ( low+) (fig24) and sections of lofexidine treated group (group IV ) showed few faint stained immune reactive cells (low+) (fig25).

Table 1: Dopamine level in cerebral cortex in different groups of male albino rats of the experiment

\begin{tabular}{|l|l|c|}
\hline Cerebral cortex & \multicolumn{1}{|c|}{ Group } & Dopamine level \\
\hline & Control & $0.801 \pm 0.009$ \\
\hline & One month tramadol intake & $0.628 \pm 0.006 *$ \\
\hline & 2 months tramadol intake & $0.520 \pm 0.005 *$ \\
\hline & Lofexidine treatment group & $0.730 \pm 0.004 *$ \\
\hline & Recovery group & $0.690 \pm 0.006 *$ \\
\hline
\end{tabular}

$*$ Changes statistically significant in comparison to corresponding control group, $P<0.001$.

Table2: Dopamine level in the thalamus in different groups of male albino rats of the experiment

\begin{tabular}{|l|l|c|}
\hline Thalamus and hypothalamus & Group & Dopamine level Mean \pm SD \\
\hline & Control & $1.329 \pm 0.023$ \\
\hline & One month tramadol & $1.056 \pm 0.012 *$ \\
\hline & 2 months tramadol & $0.876 \pm 0.012 *$ \\
\hline & Lofexidine treatment & $1.237 \pm 0.016 *$ \\
\hline & Recovery & $1.109 \pm 0.018 *$ \\
\hline
\end{tabular}

*Changes statistically significant in comparison to corresponding control group, $P<0.001$.

Table 3: Dopamine level in cerebellum in different groups of male albino rats of the experiment

\begin{tabular}{|l|l|c|}
\hline Cerebellum & \multicolumn{1}{|c|}{ Group } & Dopamine level Mean \pm SD \\
\hline & Control & $0.870 \pm 0.025$ \\
\hline & One month tramadol & $0.746 \pm 0.012 *$ \\
\hline & 2 months tramadol & $0.705 \pm 0.010 *$ \\
\hline & Lofexidine treatment & $0.796 \pm 0.014 *$ \\
\hline & Recovery & $0.768 \pm 0.016 *$ \\
\hline
\end{tabular}

$*$ Changes statistically significant in comparison to corresponding control group, $P<0.001$. 


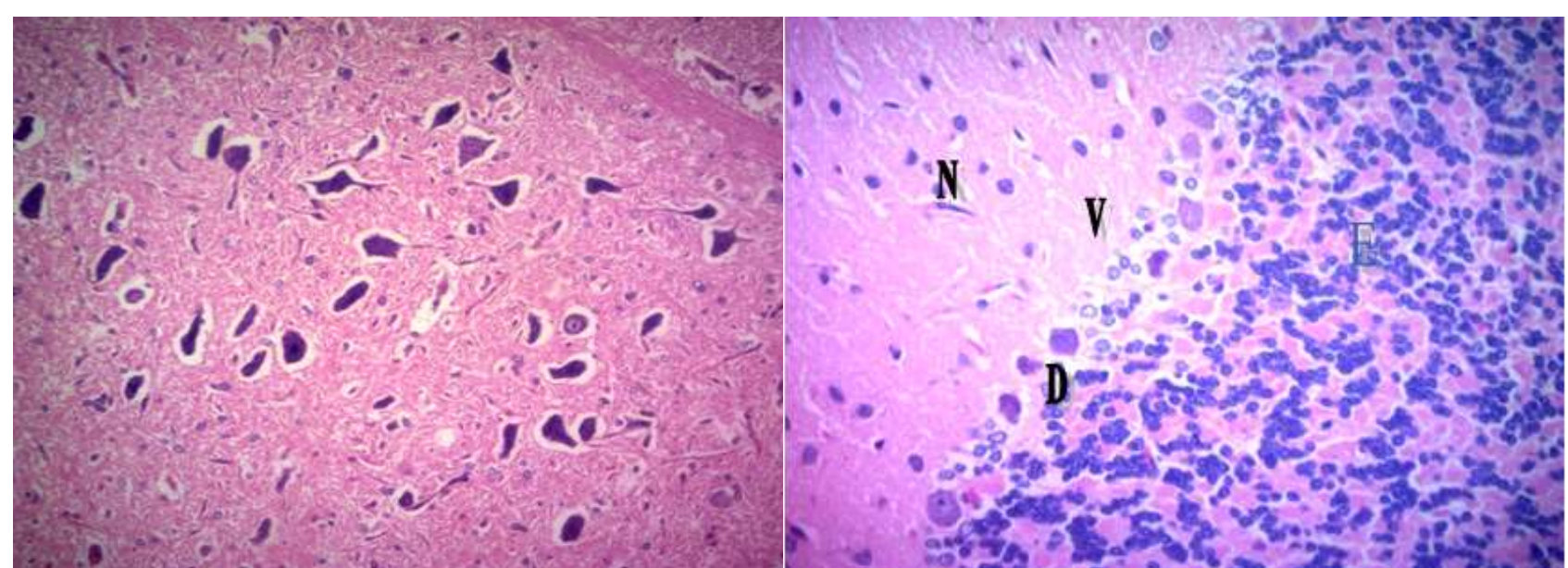

Fig. (1): Photomicrograph of control rat brain (cerebral cortex) showing normal appearance the cerebral cortex $(H x \& E, X$ 400)
Fig. (2): Photomicrograph of rat brain (cerebellum) treated with tramadol for one month showing: disorganization of cortical layer, few degenerated cells in purkenji layer (D), disarranged neuroglial cell layer (N) and multiple vacuolated cells $(\mathrm{V})$, intensively stained focal eosinophilic ( E ) areas with increased cellularity. (Hx\& E,X 400)

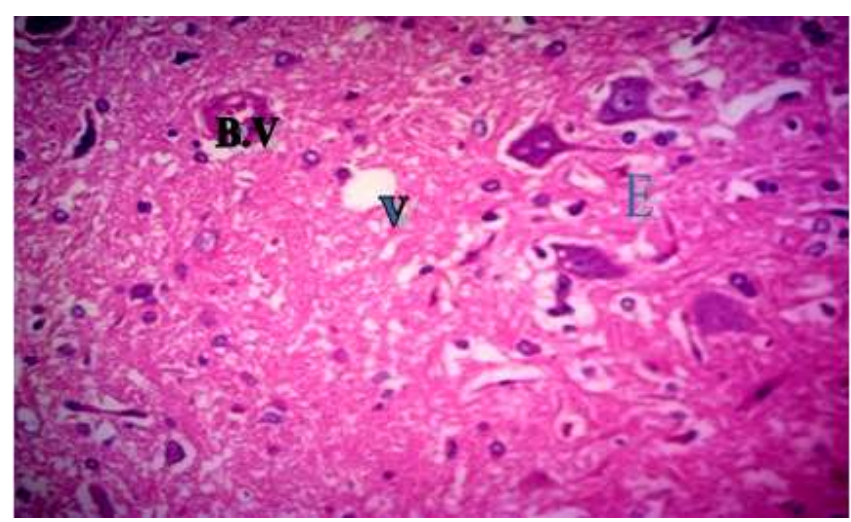

Fig. (3): Photomicrograph of rat brain (cerebral cortex) treated with tramadol for one month showing: multiple vacuolated cells (V), dilated blood vessels (B.V) (Hx\& E,X 400)

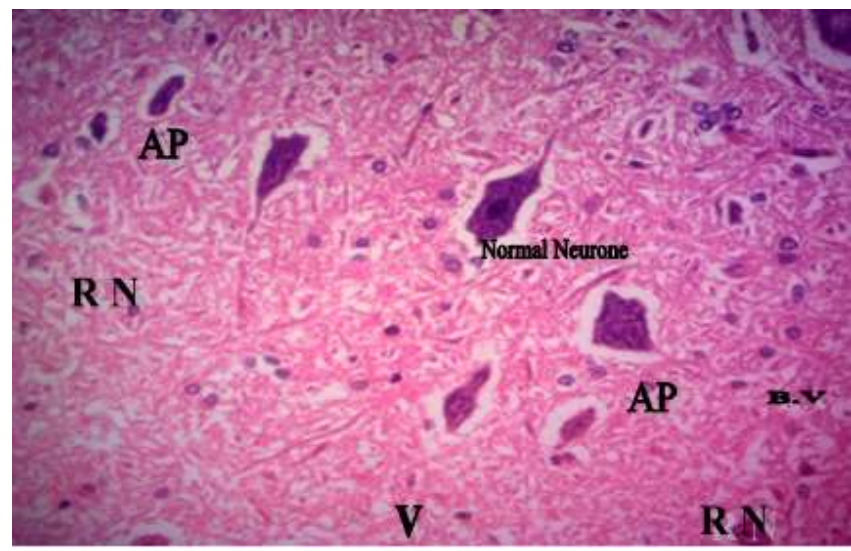

Fig. ( 5 ): Photomicrograph of rat brain (cerebral cortex) treated with tramadol for Onemonth showing: attenuated blood vessels(B.V), mild vacuolated neuropil cells (V), red neurons (R $N)$, apoptotic cells( Ap)- decreased number of neurons (Hx\& E,X 400).

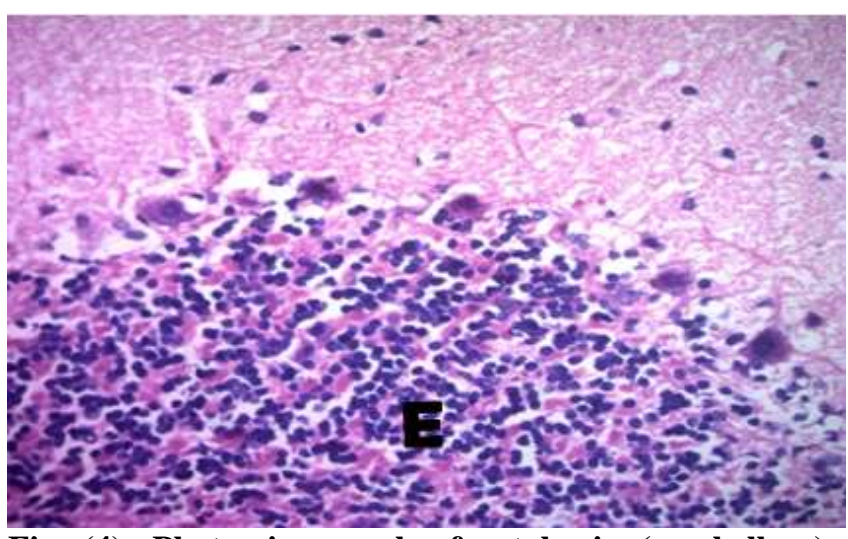

Fig. (4): Photomicrograph of rat brain (cerebellum) treated with tramadol for One month showing: intensively stained focal eosinophilic (E). (Hx\& E,X 40)

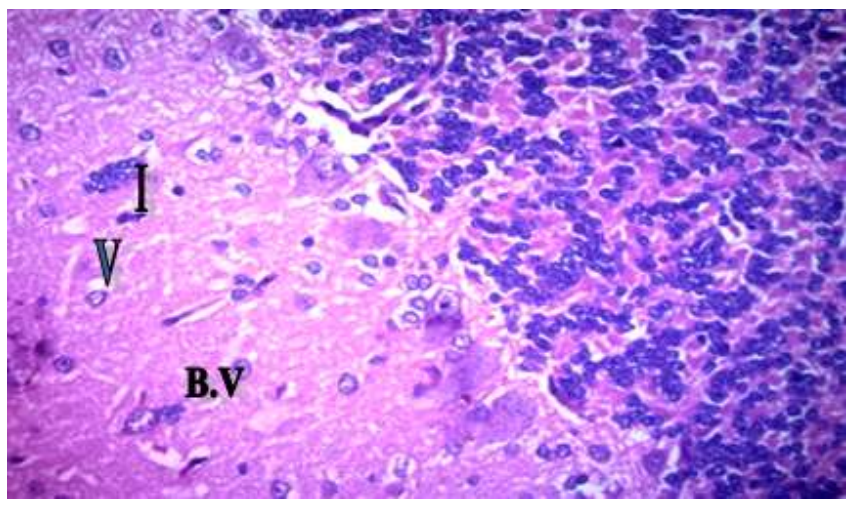

Fig. (6 ): Photomicrograph of rat brain(cerebellum) treated with tramadol for 2 months showing: marked neuronal cell degeneration( $D$ ), extensive neuropil vacuolization (V), perineuronal retraction spaces. Congested vascular channels (B.V) and cell infiltrations (I) (Hx\& E,X 400) 


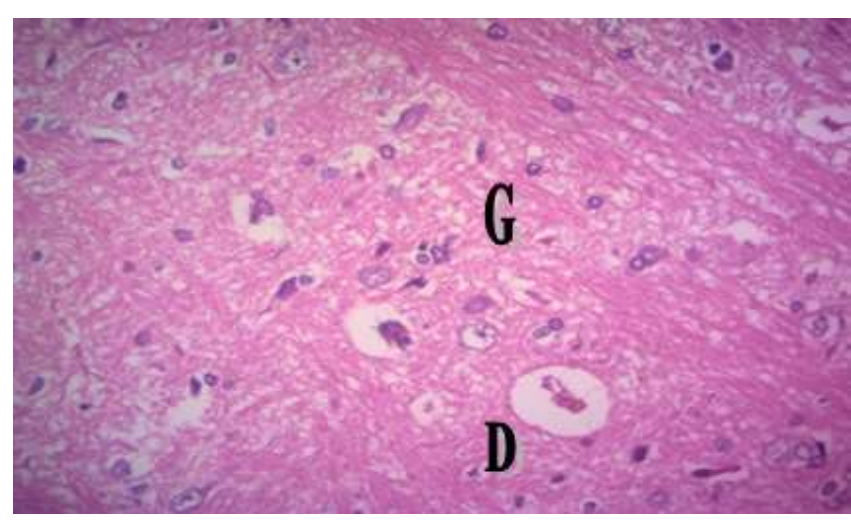

Fig. (7): Photomicrograph of rat brain (cerebral cortex) treated with tramadol for 2 months showing: neuronal cell degeneration (D) and gliosis (G) (Hx\& E, X 400)

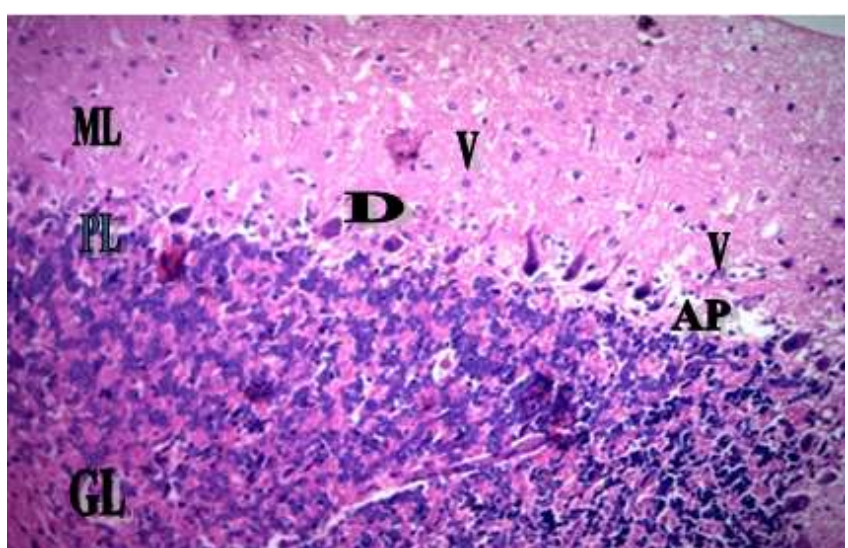

Fig. (8): Photomicrograph of rat brain (cerebellum) treated with tramadol for 2 months showing: marked neuronal cell degeneration (D), extensive neuropil vacuolization (V), gliosis of the neuropil. Presence of red neurons with prominent perineuronal retraction spaces. Congested vascular Channels (B.V) and cell infiltrations. (Hx\& E,X 400)

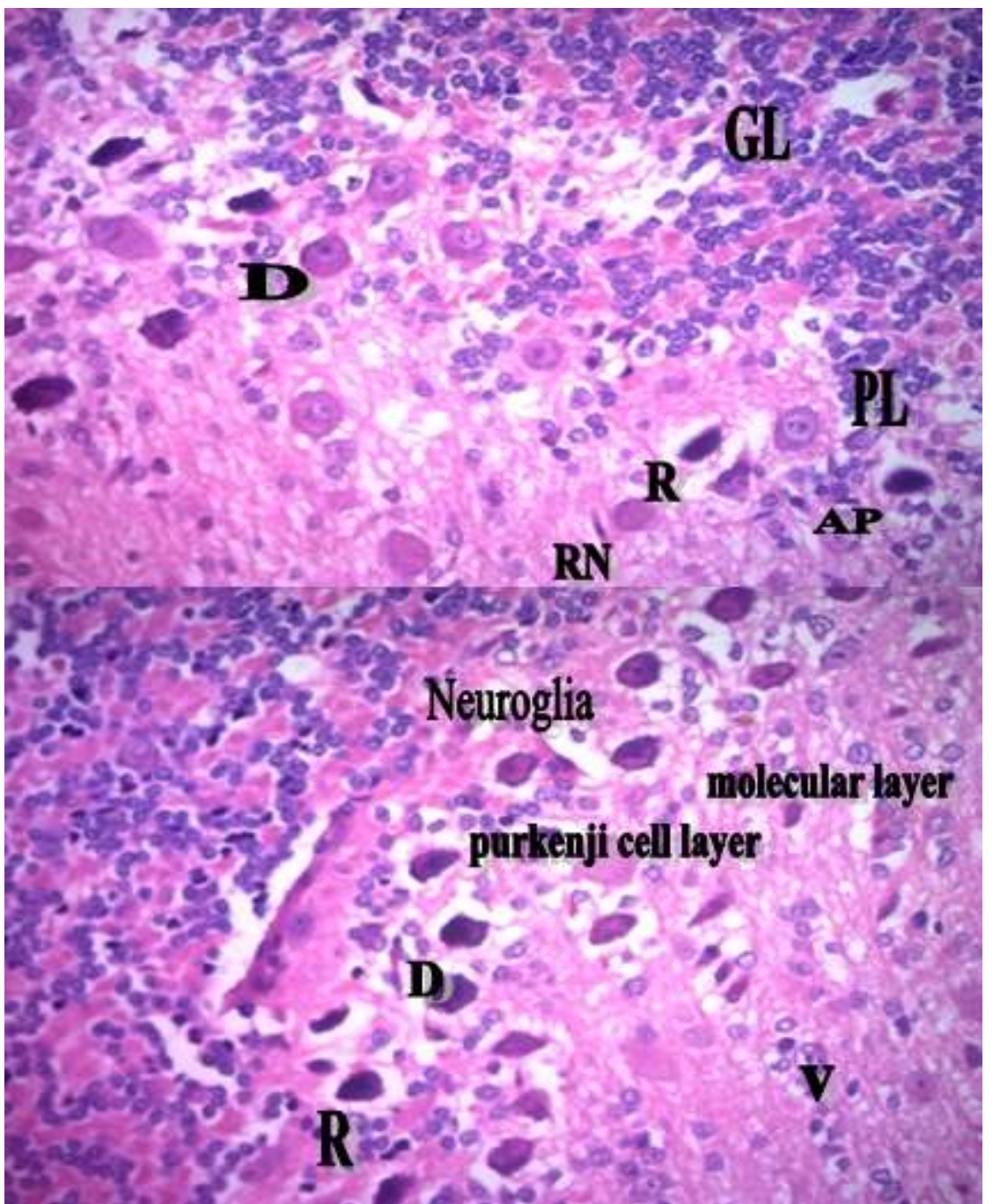

Fig. (9): Photomicrograph of rat brain (cerebellum) treated with tramadol for 2 months showing: marked neuronal cell degeneration (D), extensive neuropil vacuolization (V), gliosis of the neuropil. Presence of red neurons with prominent perineuronal retraction $(R)$ spaces. Congested vascular Channels (B.V) and cell infiltrations. (Hx\& E,X 400) 


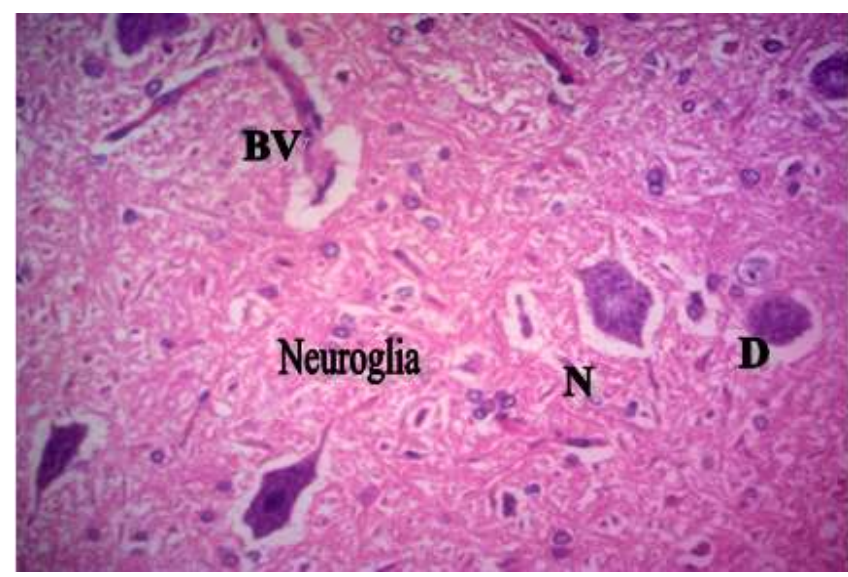

Fig. (10): Photomicrograph of rat brain (cerebral cortex) treated with tramadol for 2 months showing: marked degenerated neuronal cells (D), degenerated red neurons $(\mathrm{N})$, attenuated blood vessels (B.V) and gliosis . $\quad(H x \& E, X$ 400)

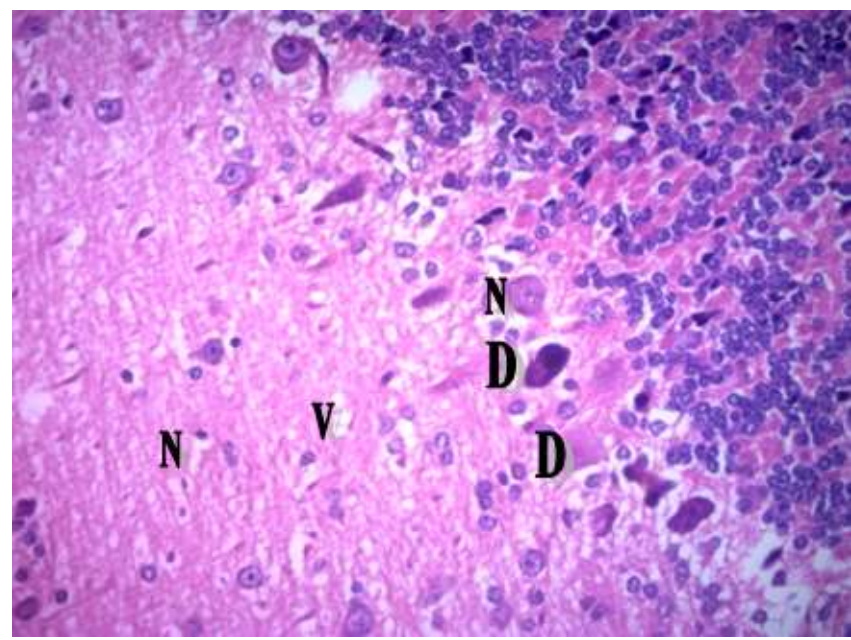

Fig. (12): Photomicrograph of rat brain (cerebellum) treated with tramadol for 2 months showing: marked neuronal cell degeneration (D), degenerated red neurons $(N)$ extensive neuropil vacuolization (V), and cell infiltrations . (Hx\& E,X 400)

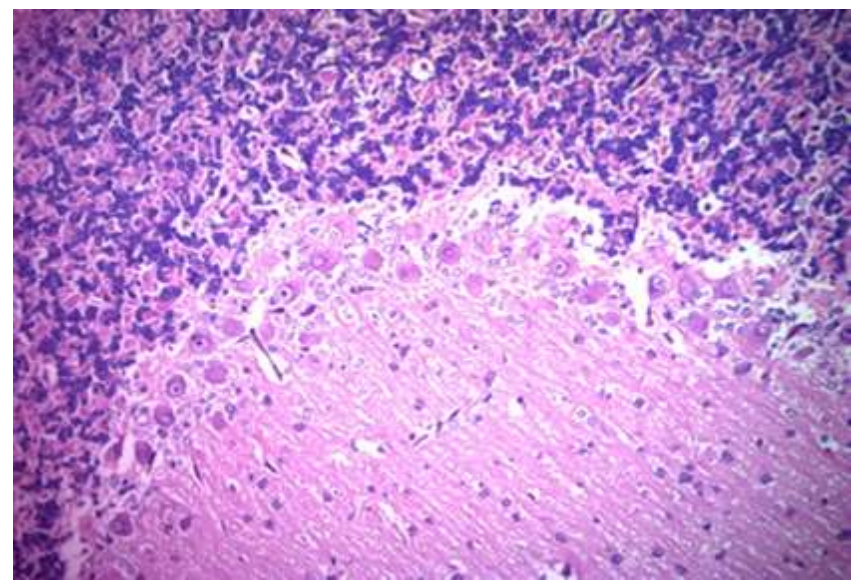

Fig. (14): Photomicrograph of rat brain (cerebellum) treated with Lofexidine: showing near normal appearance.

(Hx\& E, X 400)

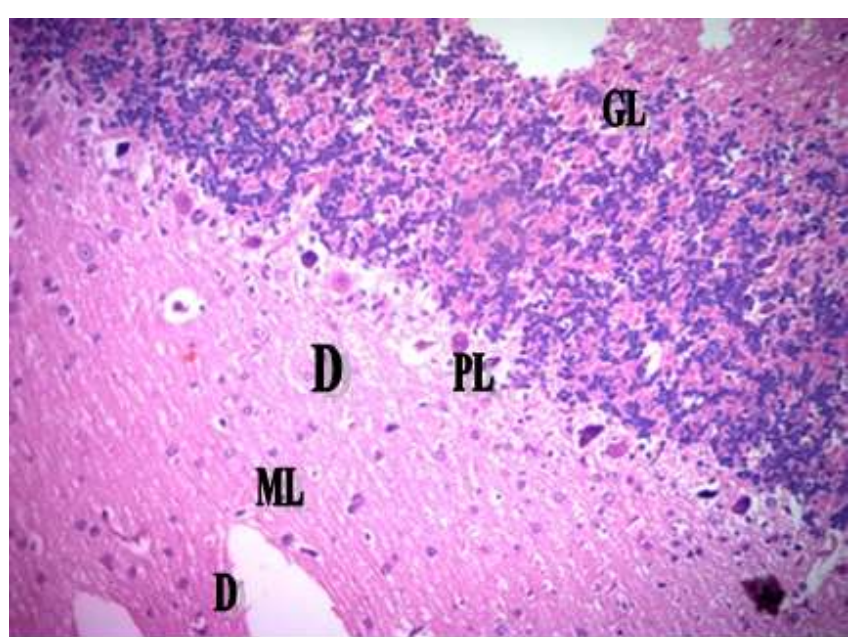

Fig. (11): Photomicrograph of rat brain (cerebellum) treated with tramadol for $\mathbf{2}$ months showing: marked neuronal cell degeneration (D), extensive neuropil vacuolization (V), gliosis of the neuropil. (Hx\& E,X 400)

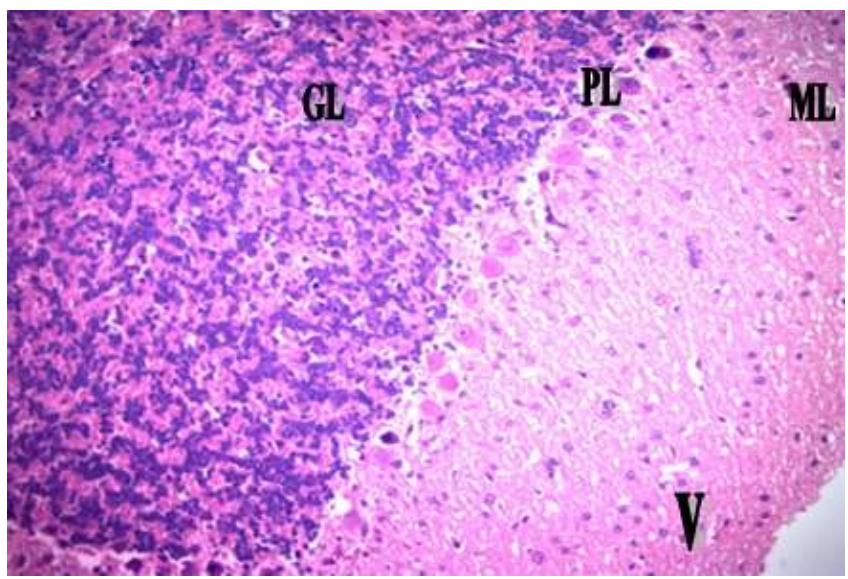

Fig. (13): Photomicrograph of rat brain (cerebellum) treated with tramadol for one month and Lofexidine for another month showing: remarkable regression of the total degenerative changes (D) - Purkenji layer began to arrange but still different with control. (Hx\& E,X 400)

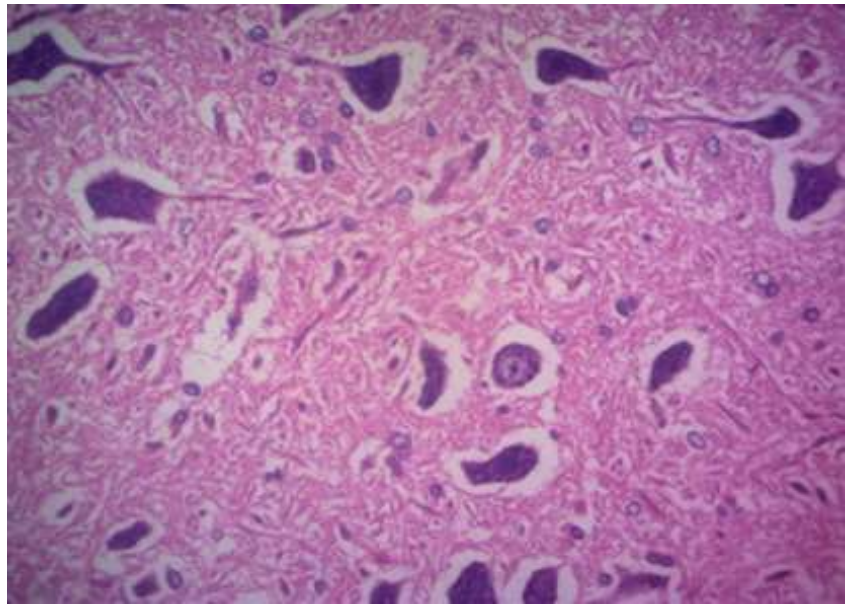

Fig. (15): Photomicrograph of rat brain (cerebral cortex) treated with Lofexidine showing: decreased vaccuolations, near normal.

(Hx\& E,X 400) 


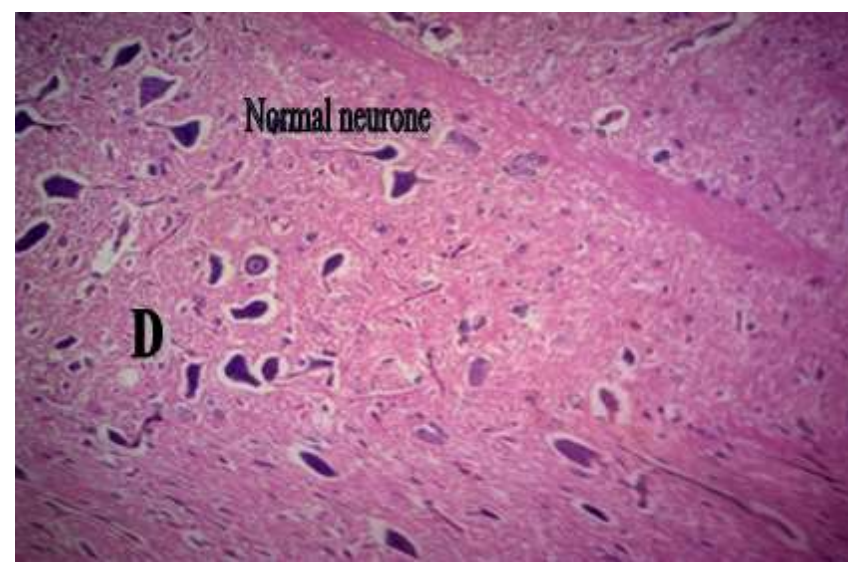

Fig. (16): Photomicrograph of rat brain (cerebral cortex) treated with Lofexidine showing: degenerated cells (D), nearly normal neuronal layer neurons begin to arrange. (Hx\& E,X 400)

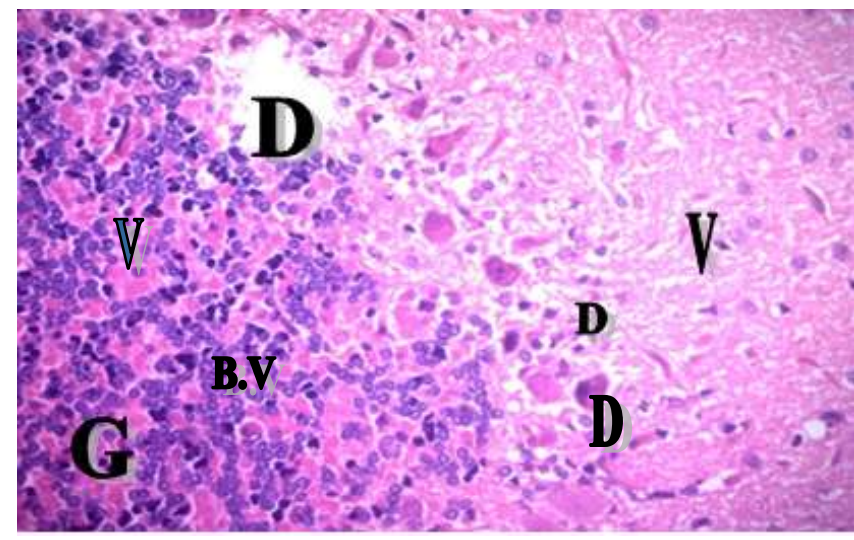

Fig. (18): Photomicrograph of rat brain (cerebellum) tissues after recovery period showed: degenerated purkenji cell layer (D), loosen and still disorganized granular layer (G), and vacuolated cells (V) slight regression of the degenerative when compared with control changes. (Hx\& E,X 400)

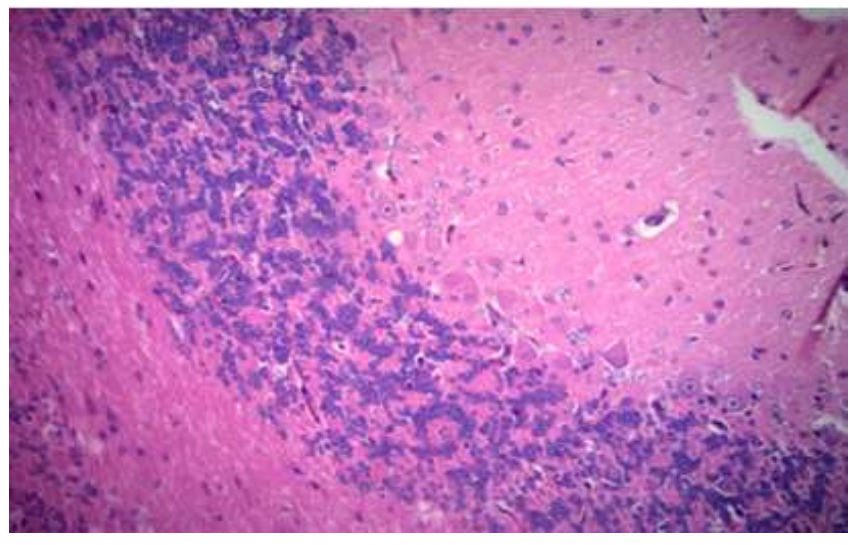

Fig. (17): Photomicrograph of rat brain (cerebellum) after recovery showing: still necrotic areas in molecular layer, congested blood vessels - slight improvement in the purkenji layer tissues showed slight regression of the degenerative changes. (Hx\& E,X 400)

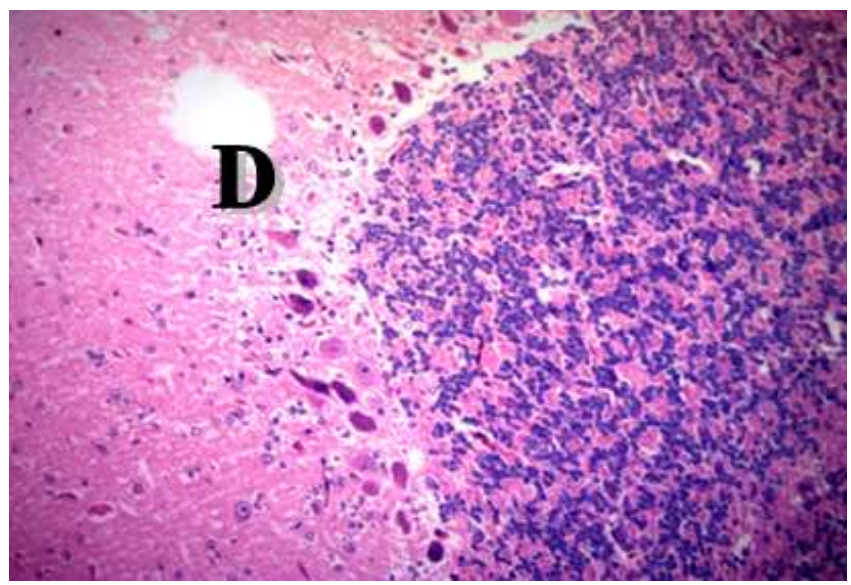

Fig. (19): Photomicrograph of rat brain (cerebellum) tissues after recovery period showed slight regression of the degenerative changes (D) when compared with control. (Hx\& E,X 400)

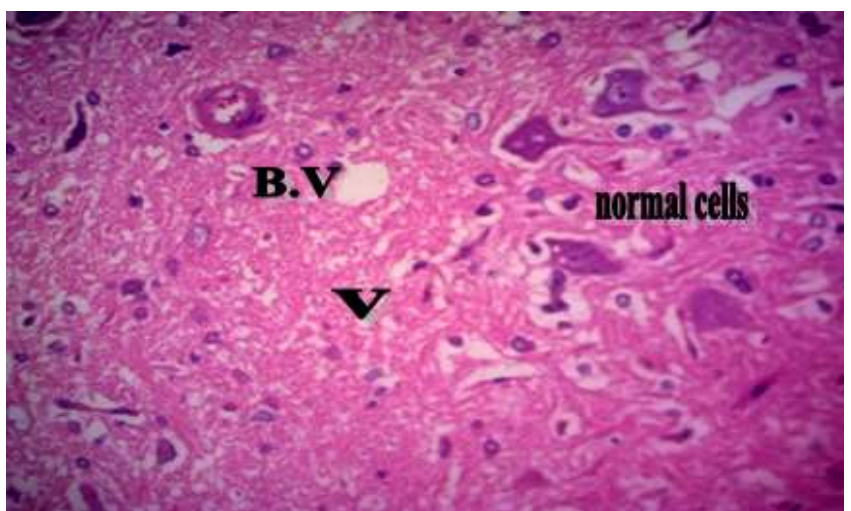

Fig. (20 ): Photomicrograph of rat brain (cerebral cortex) treated with tramadol for one month left for recovery period showing: congested blood vessels (B.V) - vaccuolation (v) - degenerated cells ( D) (Hx\& E,X 400) 


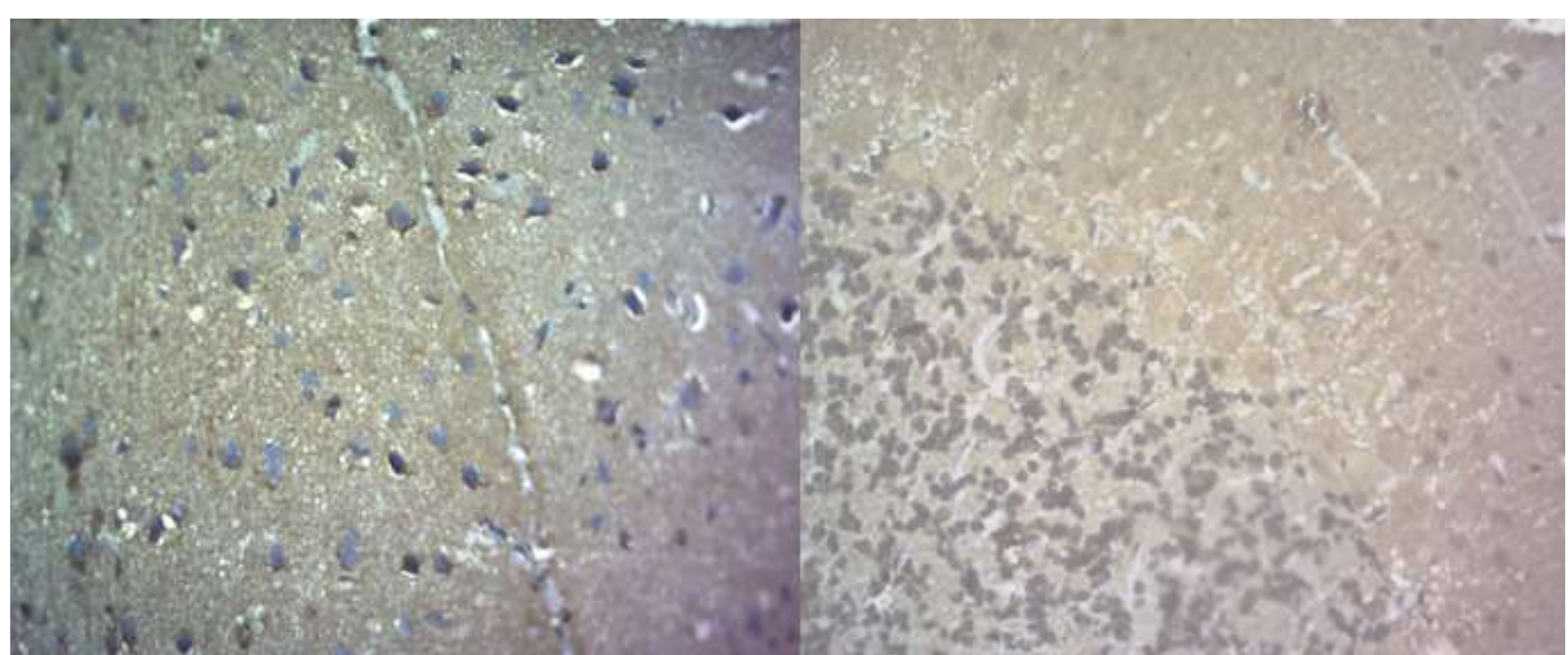

Fig. (21) Photomicrograph of Caspase-3 immunohistochemical staining of cerebellum and cerebral cortex: section of brain of normal rats (control group) showing no immune-reactive cells (-ve)

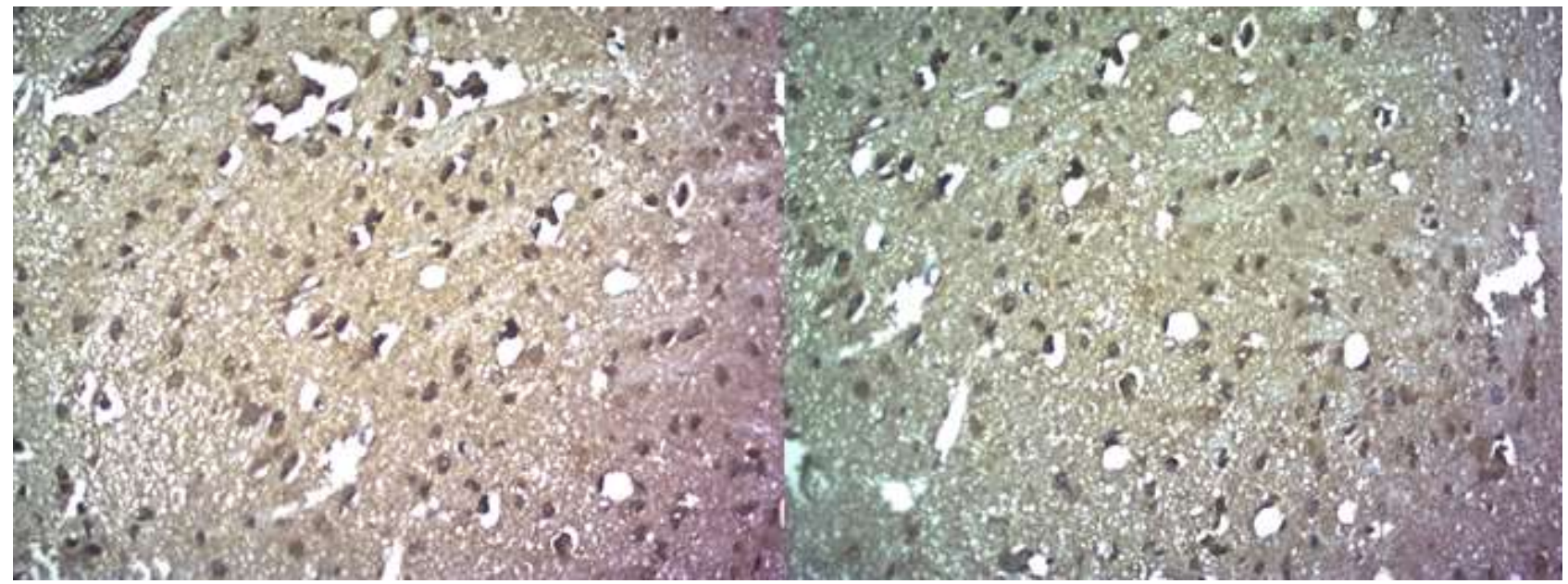

Fig. (22) Photomicrograph of Caspase-3 immunohistochemical staining of cerebral cortex: section of brain of tramadol treated rats for one month (groupII) showing moderately stained immune-reactive cells (++).

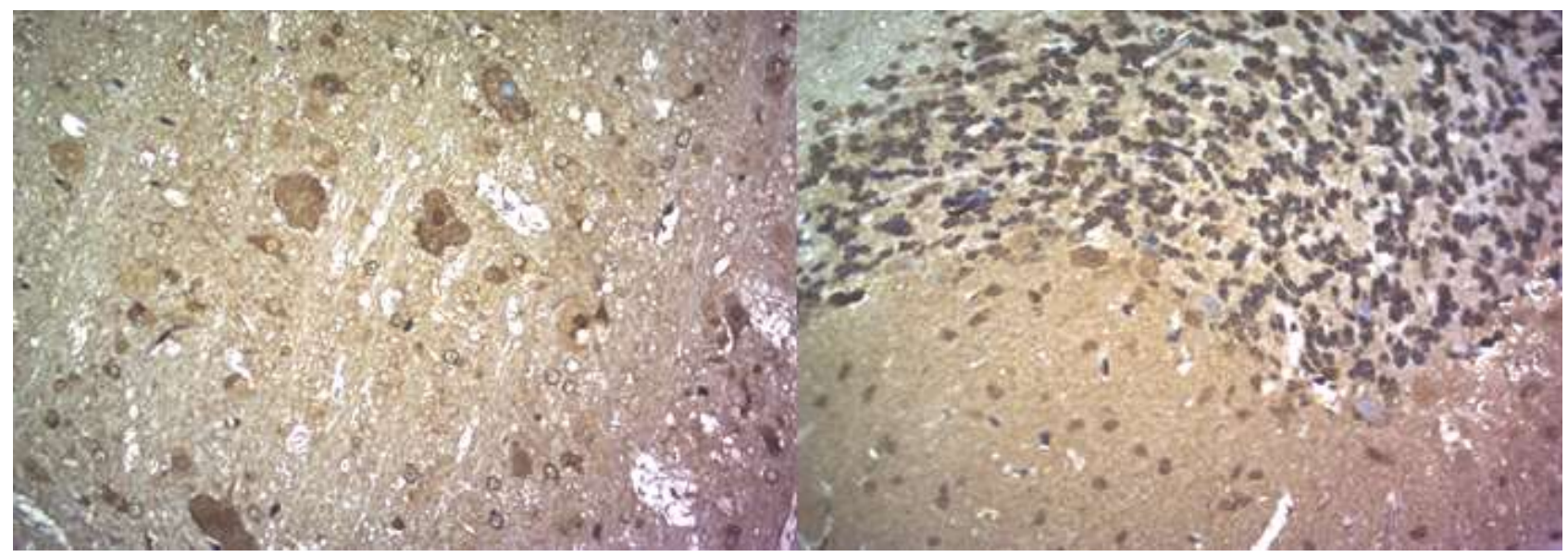

Fig. (23) Photomicrograph of Caspase-3 immunohistochemical staining of cerebral cortex and cerebellum: section of brain of tramadol treated rats for $\mathbf{2}$ month (group III) showing diffuse intensely stained immune-reactive cells (+++) 


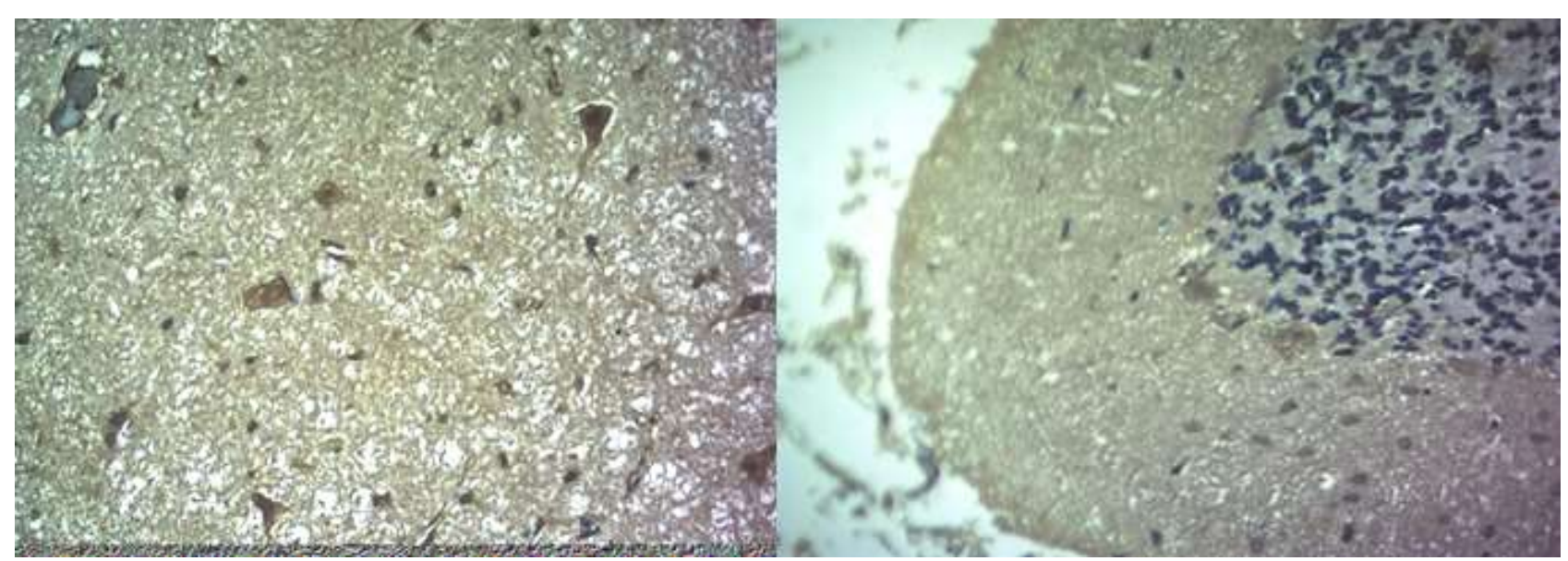

Fig. (24) Photomicrograph of Caspase-3 immunohistochemical staining of cerebral cortex and cerebellum: section of brain of recovery (group V) showing few number of faintly stained immune-reactive cells $(+)$.

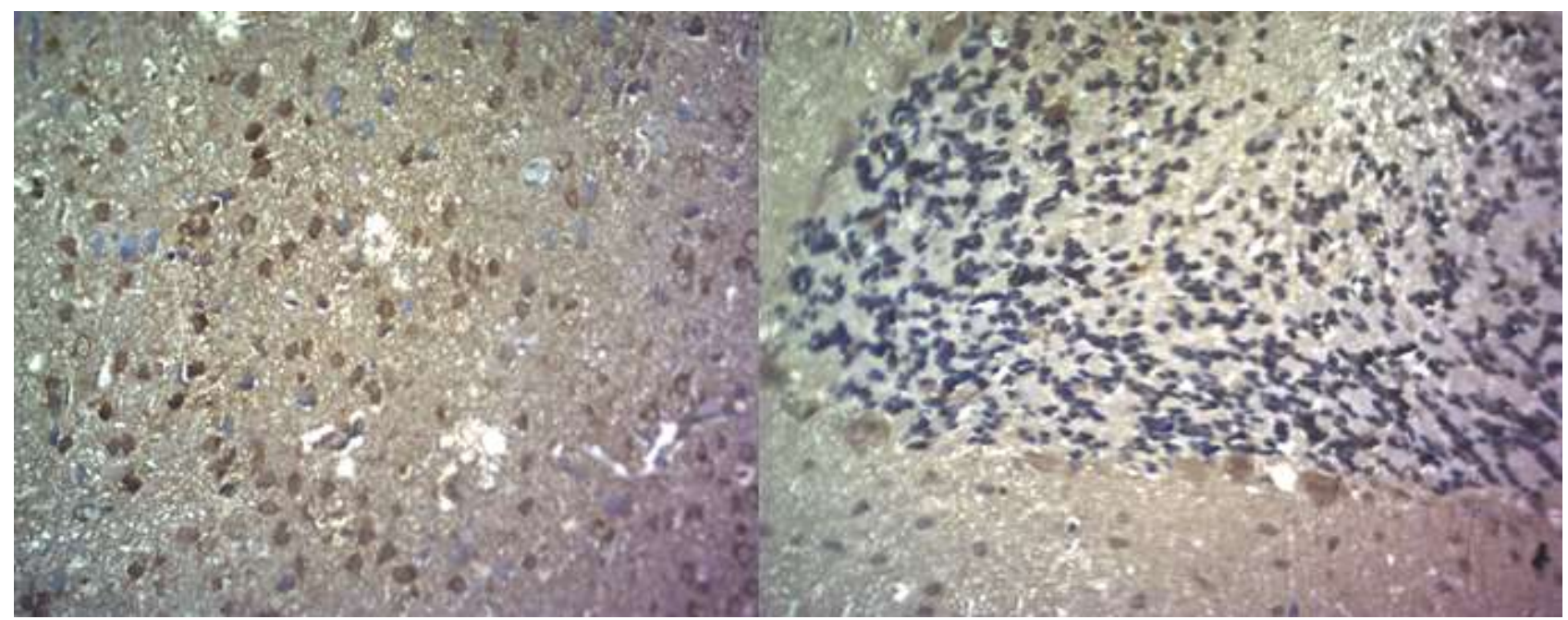

Fig. (25) Photomicrograph of Caspase-3 immunohistochemical staining of cerebral cortex and cerebellum: section of brain of lofexidine treated rats for one month after stoppage of tramadol (group IV) showing decreased numbers of immune-reactive cells $(+)$

\section{Discussion}

Regarding the observation of rats of tramadol dependent group in the present study, behavioral alterations, essentially restlessness, hyperactivity, or increased excitability and convulsion by increasing the dose, tramadol is associated with (Rafati et al., 2006) the development of physical dependence with greater abuse potential than originally believed.

(Lanier et al.2010) showed that an accumulation of the active metabolite which has a significant affinity for the mu-receptor likely leads to CNS adaptations.

Decreased dopamine levels in various parts of the brain in the present study were detected in group II and III (tramadol treated groups one and two months respectively) with some improvement in recovery group $\mathrm{V}$ and much improvement in group IV with lofexidine treatment. Decreased dopamine level (Shimomura et al., 1990) can be attributed to a reduction in DA synthesis and turnover in these brain regions as tramadol inhibited DA, NE, and 5-HT in the examined brain regions.
In general, to some extent, these effects resemble in many aspects the action of the tricyclic antidepressant drugs (Halfpenny D. M. et al., 1999)

Degenerated neuronal cells seem to be caused (Sakurai-Yamashita et al., 2003) by exhausted cells by the sustained augmented activity in response to continuous administration of Tramadol, rats exposed to stress including chemical substance, developed disturbance in the function of serotonin receptors in nerve cells and other tissues with uncontrolled cholinergic action causing vasoconstriction and ischemia.

Moreover, (Tsukada et al., 2004) clarified that stress-induced modulation of dopamine D1 and serotonin receptors functions caused by hyper activation of cyclic adenosine 3-5- monophosphate which triggered neuronal degeneration.

The observed manifestations in dependant group could be explained by (Sakurai-Yamashite et al 2003) who noticed that the histopathologic changes of brain tissues seem to be the results of neural exhaustion by the sustained augmented activity in response to continuous administration of tramadol. 
(Vizcaychipi et al 2007) also explained the observed manifestations and histopathologic changes by serotonin syndrome triggering by tramadol via partial inhibition of its uptake.

In the present study, the damaging effects of chronic tramadol administration were increased in intensity with increased period of administration (two months versus one month), (Zarnescu et al 2008) attributed these changes to the damaged cell organoid from exposure to free radicals.

Some regions of the neuropil showed dilated blood vessels, cellular infiltrate and red neurons (neurons with hypoxic changes) which coincides with the results that observed by (Mohamed et al 2013) who listed their histological finding of brain and revealed that pyramidal cells lost its shape, perivascular space increased with hemorrhage, disrupted ependyma, and choroid plexus became hypertrophied. (Abou El Fatoh et al 2014) also observed congestion of submeningeal blood vessels and neural degeneration following chronic tramadol administration. Moreover (Liu et al 2013) found that the apoptotic cells were present with cytoplasmic contraction, reduction in cell volume and nuclear condensation.

The current study showed that Casepase 3immune-histochemically positive cells which is indicated as apoptotic index was increased in group II (tramadol treated rats for one month) and with more increase in group III (tramadol treated rats for two months) while it was decreased in group IV (recovery group) and more decrease in group $\mathrm{V}$ (lofexidine treated group) when compared to group I (control group with negative results). This indicates that there is an increase in apoptosis in both cerebral cortex and cerebellum in rats receiving tramadol which subsides when the drug become withdrawn and with lofexidine treatment.

These findings coincide with that reported by.

Long term use of morphine and other opioids (Liu et al., 2013) on neuronal structure (cytoskeleton) have been regarded as a markers of neuronal damage. It may also induce the mRNA expression of proapoptotic receptors in the lymphocytes and mouse spleen, lung and heart via activating opioid receptor. large amount of apoptotic neurons were observed in the hippocampus of these rats, and the expressions of the apoptosis related proteins (Fas, Bcl-2 and caspase-3) presented with alteration.

(Atici et al 2004) concluded that chronic use of morphine and/or tramadol in increasing doses is found to cause red neuron degeneration and apoptosis in the rat brain, which probably contributes to cerebral dysfunction.

Recently, chronic treatment of rats with opiate (Sharifipour et al 2014) is associated with a remarkable upregulation of the pro-apoptotic Fas receptor, as well as intracellular pro-apoptotic elements such as caspase3.

(Atici et al., 2005) proved that chronic use of tramadol in increasing doses causes neuronal degeneration in the rat brain, which probably contributes to cerebral dysfunction. (Bloms.P. Funke et al 2011) described that Tramadol alters brain neurotransmitter levels

These cellular damaging effects noted in the present study in either histopathological, immunological and alteration in biochemical findings were decreased with some improvement of these findings in group IV (recovery group) after subside of withdrawal period morphological pattern of brain regions still showed some residual toxic effect of tramadol. After withdrawal period (Fatma M Ghoneim et al. 2014) , most of the histological findings were subsided as there was return of brain tissues towards normal morphology as evidenced by decreased cellularity and decreased perineuronal haloes as well as normal blood vessels. Multiple pyramidal cells and granular cells appeared normal; however, few pyramidal cells are shrunken and surrounded by haloes indicating that the apoptosis activity as well as the oxidative stress damage of brain tissue mostly decreased in the recovery group. (Khodeary et al., 2010) stated that rats examined after the withdrawal recovery period unlikely showed complete recovery (did not return back to normal control) but marked reduction in cellular damage was observed when compared to tramadol treated groups.

alteration in biochemical, Histopathological and immunological findings were much improved in group V ( lofexidine treated group) with return of findings to near normal which entail that use of lofexidine in treatment of chronic tramadol administration may be beneficial in protecting brain form damaging effect of tramadol in withdrawal period.

it had been demonsterated that red neurons (Atici et al.,2005) were found in tramadol and morphine groups but not in the control group, also Chronic use of tramadol in increasing doses was found to cause red neuron degeneration in the rats' brains. The authors speculated that promoted synthesis of Bax might have contributed to increased neuronal apoptosis due to chronic use of tramadol.

\section{Conclusion}

From the current study, it can be concluded that chronic Tramadol administration resulted in rats behavioral changes as restlessness, irritability and aggressive reactions. Also it decreased the dopamine levels in various brain tissues and caused marked histopathological, immunohistochemical degenerative changes on the brain and these effects increased in intensity with increased exposure period to tramadol. Some improvement was detected after stoppage and more improvement with Lefoxidine treatment.

\section{Recommendations}

The potential effects of long term tramadol therapy on the brain, and body organs should be explained to tramadol addict patients. Designing a national awareness campaign to the youth to spotlights on the health hazards of tramadol abuse, according to our results lofexidine use in treatment of chronic tramadol addiction may be helpful and future studies are recommended to explore the clinical effectiveness of lofexidine on tramadol withdrawal in human 


\section{References}

Abeer M Al-Ghananeem (2008) :Clinical

Pharmacokinetics of Lofexidine, the $\alpha$ 2-

Adrenergic Receptor Agonist, in Opiate

Addicts Plasma Using a Highly Sensitive

Liquid Chromatography Tandem Mass

Spectrometric Analysis The American Journal of Drug and Alcohol Abuse The American

Journal of Drug and Alcohol Abuse

34(5):611-6. Source: PubMed

Abou El Fatoh MF, Farag M, Sayed AE, et al.; (2014): Some Biochemical, Neurochemical, Pharmacotoxicological and Histopathological Alterations Induced by Long-term Administration of Tramadol in Male Rats. Int J Pharm Sci; 4: 565-571.

Atici S, Cinel L, Doruk N, Aktekin et al.; (2004): Opioid neurotoxicity: comparison of morphine and tramadol in an experimental rat model. Int J Neurosci; 114: 1001-11.

Atici S, Cinel I., Doruk N et al.; (2005): "Liver and kidney toxicity in chronic use of opioids: an experimental long term treatment model," Journal of Biosciences, vol. 30, no. 2, pp. 245-252.

Bermawy El-, Manal I.; Salem, et al.; (2015): Histological changes of the albino rat cerebellar cortex under the effect of different doses of tramadol administration, The Egyptian Journal of Histology: Volume 38 Issue 1 - p 143-155.

Bloms-Funke P, Dremencov E, Cremers T. et al.; (2011) : "Tramadol increases extracellular levels of serotonin and noradrenaline as measured by in vivo microdialysis in the ventral hippocampus of freely-moving rats," Neuroscience Letters, vol. 490, no. 3, pp. 191-195.

Ciarlone A. E. (1978) "Further modification of a fluorometric method for analyzing brain amines," Microchemical Journal, vol. 23, no. 1, pp. 9-12 .

Cox, S. and Alcorn, A. (1995): Lofexidine and opioid withdrawal. Lancet, 345, 1385-1386.

Epstein DH, Preston KL, Jasinski DR (2006): Abuse liability, behavioural pharmacology, and physical-dependence potential of opioids in humans and laboratory animals: lessons from tramadol, Biological Psychology journal;73 (1 ):90-95.

Fatma M Ghoneim, Hanaa A Khalaf, Ayman Z Elsamanoudy et al.; (2014) : Effect of chronic usage of tramadol on motor cerebral cortex and testicular tissues of adult male albino rats and the effect of its withdrawal: histological, immune-histochemical and biochemical study. Int J Clin Exp Pathol; 7(11):7323-7341.

Halfpenny D. M, Callado L. F., Hopwood S. et al.; (1999) : "Effects of tramadol stereoisomers on norepinephrine efflux and uptake in the rat locus coeruleus measured by real time voltammetry," British Journal of Anaesthesia, vol. 83, no. 6, pp. 909-915.
Hara K, Minami K, Sata T (2005): "The effects of tramadol and its metabolite on glycine, gamma-aminobutyric acid, and N-methyl-Daspartate receptors expressed in Xenopus oocytes". Anesthesia and Analgesia 100 (5): 1400-5,.PMID 15845694.

Khodeary MF, Sharaf El-Din AI, El Kholy.A (2010): histopathological and immunohistochemical study of adult rats'brain after long term exposure to amadol (tramadol hydrochloride). Mansoura J Forensic Med Clin.Toxicol.; 18: 1-24.

Krajewska M, Wang $\mathrm{H}-\mathrm{G}$, Krajewski $\mathrm{S}$, et al. (1997):Immunohistochemical analysis of in vivo patterns of expression of CPP32 (Caspase-3), a cell death protease. Cancer Res.; 57(8):1605-13.

Langley PC, Patkar AD, Boswell KA, et al. (2010): Adverse event profile of tramadol in recent clinical studies of chronic osteoarthritis pain, Current Medical Research and Opinion journal; 26 (1):239-51.

Lanier R, K,; Lofwall M, R,; Mintzer M, Z et al. (2010). Physical dependence potential of daily tramadol dosing in humans. Psychopharmacology. (Berl). 211(4): 457466.

Lintz W, Barth H, Osterloh G, et al., (1998):

Pharmacokinetics of tramadol and bioavailability of enteral tramadol formulations. 3rd communication: suppositories. Arzneimittel.Forschung., 48 (9): 889-99.

Liu L.W, Lu J, Wang XH, et al. (2013): Neuronal apoptosis in morphine addiction and its molecular mechanism. Int J Clin Exp Med; 6: 540-5.

McKeon G, P; Pacharinsak C, Long C,T, et al. (2011). Analgesic effects of tramadol, tramadol gabapentin, and buprenorphine in an incisional model of pain in rats (Rattus norvegicus). J. Biol. Chem., 286 (18):1618696.

Mohamed TM, Abdel Ghaffar HM, El Husseiny RM. (2013): Effects of tramadol, clonazepam and their combination on brain mitochondrial complexes in Toxicology and Industrial Health 31(12) · Source: PubMed

Paget G, E and Barnes J, M (1964). "Evaluation of Drug Activities and Pharmacometrics". Academic Press, London, pp.135-166.

Popovic M, Janicijevic-Hudomal S, Kaurinovic B, et al.; (2009): Antioxidant effects of some drugs on immobilization stress combined with cold restraint stress. Molecules 2009, 14(11), 45054516

Rafati A, Yasini SM, Dashti-Rahmatabadi MH, et al.; (2006): Tramadol Dependence Rate as Compared with Morphine in Rats. W J Med Sci 1(1): 40-43.

Raffa R, (2006): Pharmacological aspects of successful long-term analgesia, Clin.Rheumatol. 25 (1): S9-S15. 
Riedl SJ, ShiY. et al.; (2004): Molecular mechanism of caspase regulation during apoptosis. Mol Cell Biol; 5:897-907.

Sakurai-Yamashita, Y.; Yamashita, K.; Niwa, M.; et al. (2003): "Involvement of 5-hydroxytryptamine 4 receptor in the exacerbation of neuronal loss by psychological stress in the hippocampus of SHRSP with a transient ischemia". Brain Res., 973: 92-98.

Sansone R, A, and Sansone L, A, (2009): Tramadol, seizures, serotonin syndrome, and coadministered antidepressants. Psychiatry (Edgmont), 6(4):17-21.

Sastry, P. S., and Rao, K. S. (2000):.Apoptosis and the nervous system. Journal of Neuro-chemistry, 74, 1-20.

Sharifipour M, Izadpanah E, Nikkhoo B, et al.; (2014): new pharmacological role for donepezil: attenuation of morphine-induced tolerance and apoptosis in rat central nervous system. J Biomed Sci; 23: 21-34.

Shimomura Y, Shimizu H, Takahashi M, Uehara Y, et al. (1990): "Ambulatory activity and dopamine turnover in streptozotocin-induced diabetic rats," Experimental and Clinical Endocrinology, vol. 95, no. 3, pp. 385-388,.

Tsukada, H.; Fukumoto, D.; Nishiya-ma, S.; et al. (2004):"Transient focal ischemia affects the cAMP second messenger system and coupled dopamine D1 and 5-HT1A receptors in the living monkey brain: a positron emission tomography study using microdialysis Cereb. Blood Flow Metab.synapse,52:1-10.

Vizcaychipi MP, Walker S and Palazzo M (2007): Serotonin syndrome triggered by tramadol $\mathrm{Br}$. J. Anaesth., 99 (6): 919. Brian Res., 973(1): 92-98.

Waltereit R, Weller M. (2002): The role of caspases 9 and 9-short (9S) in death ligand- and druginduced apoptosis in human astrocytoma cells. Mol Brain Res; 106:42-49.

Xiao, Y., He, J. H., Gilbert, R. D. (2000): Cocaine induces apoptosis in fetal myocardial cells through a mitochondria-dependent pathway. The Journal of Pharmacology and Experimental Therapeutics, 292, 8-14.

Yuan, J., \&Yankner, B. A. (2000): Apoptosis in the nervous system. Nature, 407, 802-809.

Zarnescu O, Brehar FM, Chivu M, et.al. (2008): Immunohistochemical localization of caspase3, caspase-9 and Bax in U87 glioblastoma xenografts. J Mol. Histol; 39: 561-569.

Zoe Clarke (2007): The Comprehensive Pharmacology Reference 2007 Chapter: Lofexidine Pages 14.in xPharm library . University of Wales College of Medicine, Cardiff, United Kingdom Available online 10 January 2008. 


\section{الملخص العربي}

\section{آثار إدمان الترامادول علي المخ في ذكور فئران التجارب البيضاء البالغه ودور اللوفيكسيدين

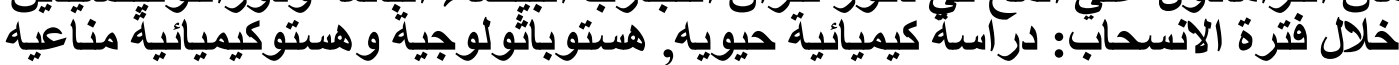

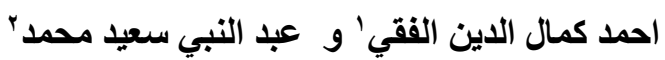

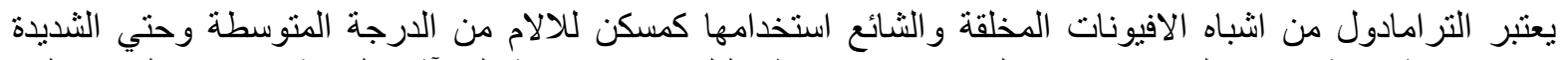

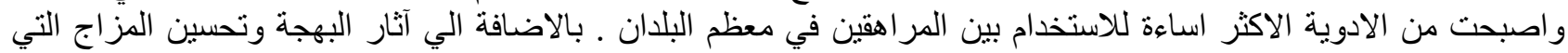

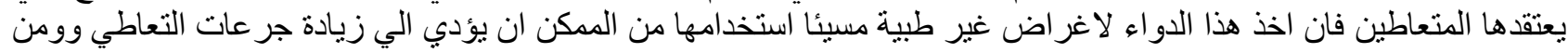
ثم الي الادمان.

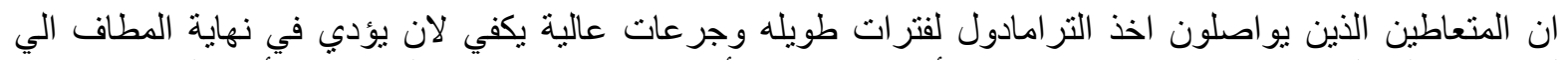

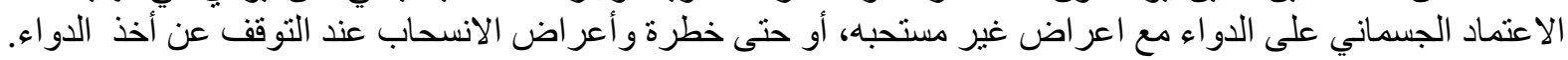

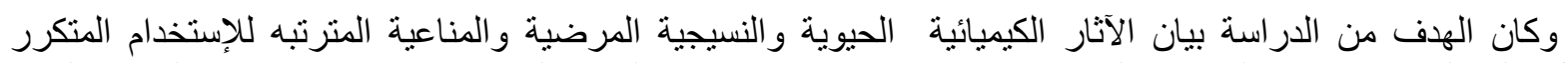

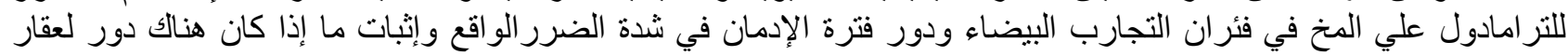

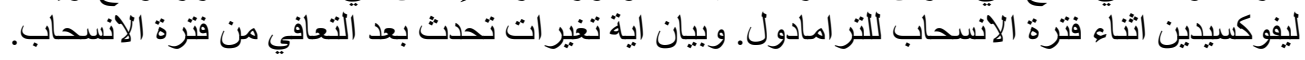

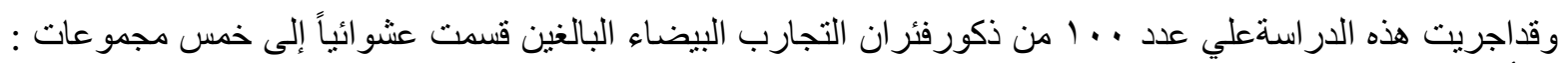

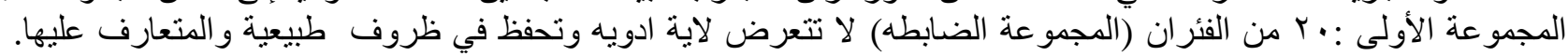

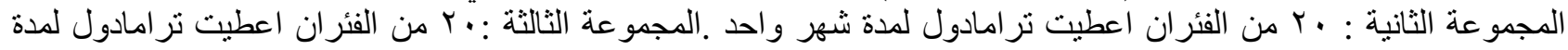

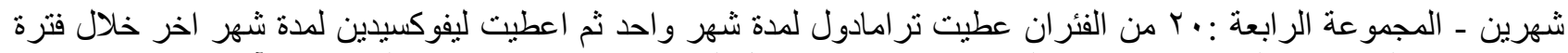

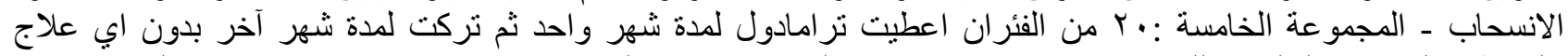

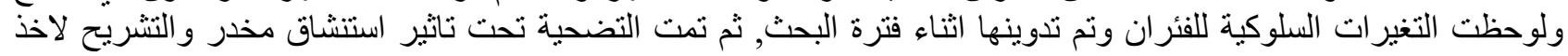

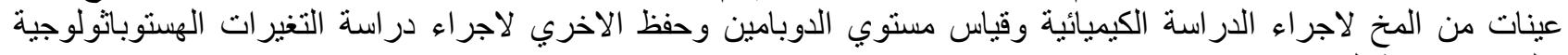
و الهسنوكيميائية المناعيا.

اعطيت الجر عات عن طريق الفم ( ترامادول مذاب في المحلول الملحي ) ودرست التغيير ات في أنسجة المخ للفئران في

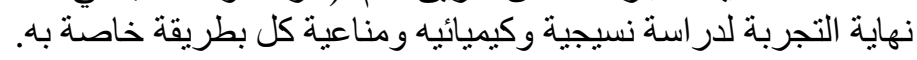

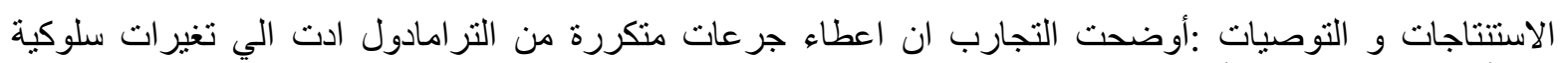

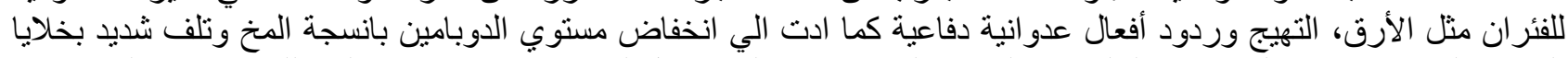

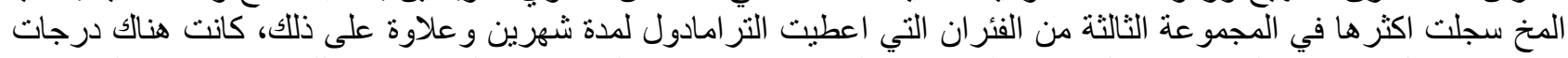

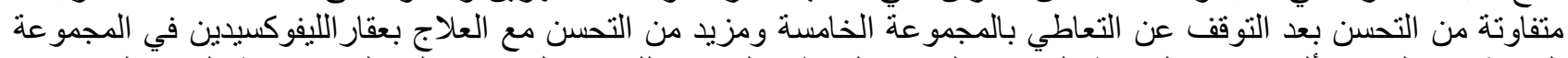

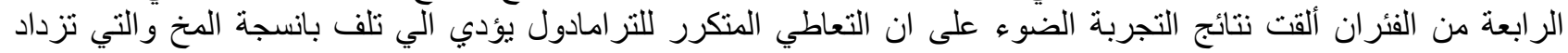

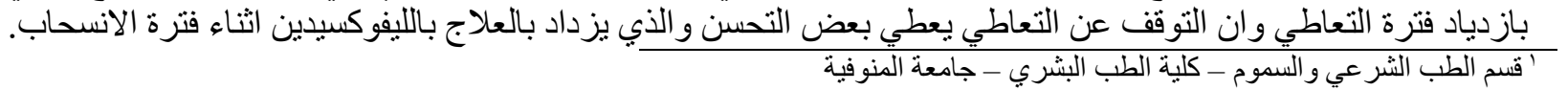

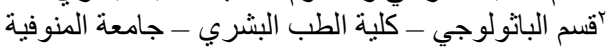

